\title{
MicroRNA profiling in ischemic injury of the gracilis muscle in rats
}

\author{
Ching-Hua Hsieh*1, Jonathan Chris Jeng², Seng-Feng Jeng ${ }^{1}$, Chia-Jung Wu1', Tsu-Hsiang Lu'1, Po-Chou Liliang³, \\ Cheng-Shyuan Rau ${ }^{4}$, Yi-Chun Chen ${ }^{1}$ and Chia-Jung Lin ${ }^{1}$
}

\begin{abstract}
Background: To profile the expression of microRNAs (miRNAs) and their potential target genes in the gracilis muscles following ischemic injury in rats by monitoring miRNA and mRNA expression on a genome-wide basis.

Methods: Following $4 \mathrm{~h}$ of ischemia and subsequent reperfusion for $4 \mathrm{~h}$ of the gracilis muscles, the specimens were analyzed with an Agilent rat miRNA array to detect the expressed miRNAs in the experimental muscles compared to those from the sham-operated controls. Their expressions were subsequently quantified by real-time reverse transcription polymerase chain reaction (real-time RT-PCR) to determine their expression pattern after different durations of ischemia and reperfusion. In addition, the expression of the mRNA in the muscle specimens after $4 \mathrm{~h}$ of ischemia and reperfusion for 1, 3, 7, and $14 \mathrm{~d}$ were detected with the Agilent Whole Rat Genome $4 \times 44 \mathrm{k}$ oligo microarray. A combined approach using a computational prediction algorithm that included miRanda, PicTar, TargetScanS, MirTarget2, RNAhybrid, and the whole genome microarray experiment was performed by monitoring the mRNA:miRNA association to identify potential target genes.

Results: Three miRNAs (miR-21, miR-200c, and miR-205) of 350 tested rat miRNAs were found to have an increased expression in the miRNA array. Real-time RT-PCR demonstrated that, with 2-fold increase after $4 \mathrm{~h}$ of ischemia, a maximum 24-fold increase at $7 \mathrm{~d}$, and a 7.5-fold increase at $14 \mathrm{~d}$ after reperfusion, only the miR-21, but not the miR$200 \mathrm{c}$ or miR-205 was upregulated throughout the experimental time. In monitoring the target genes of miR-21 in the expression array at 1, 3, 7, $14 \mathrm{~d}$ after reperfusion, with persistent expression throughout the experiment, we detected the same 4 persistently downregulated target genes (Nqo 1, Pdpn, CXCL3, and Rad23b) with the prediction algorithms miRanda and RNAhybrid, but no target gene was revealed with PicTar, TargetScanS, and MirTarget2.
\end{abstract}

Conclusions: This study revealed 3 upregulated miRNAs in the gracilis muscle following ischemic injury and identified 4 potential target genes of miR-21 by examining miRNAs and mRNAs expression patterns in a time-course fashion using a combined approach with prediction algorithms and a whole genome expression array experiment.

\section{Background}

Skeletal muscle ischemia is an important clinical problem that may result in a significant high rate of morbidity and mortality. Despite extensive experimental work that is directed toward the treatment and prevention of established ischemic injuries, the clinical outcome has not appreciably changed over the past decades [1]. This may be related to the fact that the pathophysiology of this complex event is still incompletely understood. The

\footnotetext{
* Correspondence: m93chinghua@gmail.com

1 Department of Plastic and Reconstructive Surgery, Chang Gung Memorial Hospital, Kaohsiung Medical Center, Chang Gung University College of Medicine, Taiwan

Full list of author information is available at the end of the article
}

microRNAs (miRNAs) are a novel regulatory class of noncoding, single-stranded RNAs of approximately 22 nucleotides, which have recently been identified to play critical roles in normal development and physiology, as well as in disease development $[2,3]$. The discovery of miRNAs has broadened the overall understanding of the mechanisms that regulate gene expression, with the addition of an entirely novel level of regulatory control. Both basic and clinical studies suggest that miRNAs are important regulators of cell differentiation, growth, proliferation, and apoptosis [4-6]. Estimates indicate that miRNAs may regulate up to one-third of the mammalian genome [7]. However, each miRNA possibly targets many differ- 
ent mRNAs and the same target gene may be regulated by a given miRNA in different situations, allowing for enormous complexity and flexibility in their regulatory potential [7-9]. Therefore, although a large number of miRNAs have been discovered, only a few target genes have been identified and the functions of most of them remain unknown.

The miRNAs repress protein expression at the posttranscriptional level, mostly through base pairing to the 3 untranslated region (UTR) of the target mRNA, thus leading to its degradation and/or reduced translation. Earlier, miRNAs were thought to primarily repress their target genes at the protein level without affecting mRNA stability $[10,11]$; however, increasing evidence indicates that miRNAs silence genes by multiple mechanisms, including the degradation of their target mRNAs $[12,13]$. For the more highly repressed targets, mRNA destabilization usually constituted the major component of repression [14], thus making the investigation of the mRNA:miRNA association by monitoring miRNA and mRNA expression on a genome-wide basis a novel analytical approach to understand the miRNA-mediated regulation [15,16].

Dysregulated miRNA expression has been reported to be involved in the transient focal ischemic brain $[16,17]$ and in the ischemia-reperfusion injury of the heart $[18,19]$. In addition, the endogenously synthesized miRNAs demonstrated to be cardioprotective following ischemia-reperfusion injury [19]. Moreover, there is increasing evidence for the involvement of microRNA in myopathies [20-22]; a number of microRNAs have been characterized as regulators of skeletal muscle development and diseases [23,24] as well as of skeletal muscle remodeling [25]. Given the importance of miRNAs in the pathophysiology of the muscle, we hypothesized that microRNAs could be involved in the skeletal muscle in response to ischemic injury. First, we addressed this hypothesis using a microarray-based screening. The expression profile was subsequently verified with realtime reverse transcription polymerase chain reaction (real-time RT-PCR). Potential target genes were identified by monitoring the miRNA and mRNA expression on a genome-wide basis.

\section{Methods}

\section{Animal surgery and tissue preparation}

The experiments were performed on adult male SpragueDawley rats weighing 250-300 g. The rats were randomly assigned to the sham-operated control group and the ischemic group. The rats were anesthetized by an intraperitoneal injection of $500 \mathrm{mg} / \mathrm{kg}$ chloral hydrate and prepared in the prone position. The gracilis muscle flap was dissected under the microscope by the same surgeon. The flap was isolated on its dominant and minor vascular pedicles. We used a standard microvascular technique for the sham-operated control group. The minor vascular pedicle was electrocauterized and transected. Ischemia was induced in the ischemic group by placing a microvascular clamp carefully across the proximal dominant vascular pedicle to the gracilis muscle. The gracilis muscle was allowed to perfuse in the sham-operated control group. After the indicated ischemic time $(0.5,1,2$, and 4 $\mathrm{h}$ ), the microvascular clamp was removed. Good vascular inflow and outflow through the pedicle was verified under direct magnified vision. The incision wound was closed with interrupted sutures (4-0 nylon) and the animals were allowed to awaken in the remaining periods of reperfusion. For the miRNA array experiments, gracilis muscles after $4 \mathrm{~h}$ of ischemia and $4 \mathrm{~h}$ of reperfusion were used in 2 replicate experiments. First, we performed evaluation experiments to determine the minimal ischemic time that would induce miRNA expression before we investigated the miRNA expression in the real-time RTPCR experiments. For that, the muscle specimens were either harvested after $4 \mathrm{~h}$ of ischemia and reperfusion for $0,2,4,8$, and $24 \mathrm{~h}$ and for 3,7 , and $14 \mathrm{~d}$ or the ischemia times were set at $0.5,1$, and $2 \mathrm{~h}$ with perfusion for $4 \mathrm{~h}$. We used the muscle specimens that underwent ischemic injury at 1, 3, 7, and $14 \mathrm{~d}$ after reperfusion for the whole genome expression experiments. The harvested muscles were frozen in isopentane chilled in liquid nitrogen and stored at $-80^{\circ} \mathrm{C}$. All housing, surgical procedures, analgesia, and assessments were performed in accordance with the Animal Care Guidelines and were approved by the Animal Care Committee at the Chang Gung Memorial Hospital.

\section{RNA isolation}

Total RNA was extracted using the mirVana miRNA Isolation kit (Ambion, Austin, TX, USA). The purified RNA was quantified by determining the absorbance at $260 \mathrm{~nm}$ using an SSP-3000 Nanodrop spectrophotometer (Infinigen Biotech, City of Industry, CA, USA). The quality of the purified RNA was evaluated on a Bioanalyzer 2100 (Agilent Technologies, Palo Alto, CA, USA) for the miRNA array and whole genome expression analyses.

\section{Expression of miRNAs}

A rat miRNA array (G4473A, Agilent Technology) which includes 350 rat miRNAs (Sanger miRBase Release 10.1) was used to identify the upregulated miRNAs in the gracilis muscles after $4 \mathrm{~h}$ of ischemia and $4 \mathrm{~h}$ of reperfusion, with total four one-color miRNA arrays for two shamoperated and two experimental muscle specimens. One hundred nanogram of total RNA was dephosphorylated for $30 \mathrm{~min}$ at $37^{\circ} \mathrm{C}$ with 11.2 units calf intestine alkaline phosphatase (GE Healthcare Life Sciences, Uppsala, Sweden). The reaction was terminated by heating at $100^{\circ} \mathrm{C}$ for 
$5 \mathrm{~min}$ and immediate cooling to $0^{\circ} \mathrm{C}$. DMSO $(5 \mu \mathrm{l})$ was then added. The solution was heated to $100^{\circ} \mathrm{C}$ for $5 \mathrm{~min}$ and immediately cooled to $0^{\circ} \mathrm{C}$. Ligase buffer and BSA were added and ligation was performed by adding $\mathrm{pCp}$ Cy3 $(50 \mu \mathrm{M})$ and 15 units T4 RNA ligase in $28 \mu \mathrm{l}$. The mixture was incubated at $16^{\circ} \mathrm{C}$ for $2 \mathrm{~h}$. The labeled miRNAs were desalted with MicroBioSpin6 columns (BioRad, Hercules, CA, USA). Subsequently, $2 \times$ hybridization buffer was added to the labeled mixture to a final volume of $45 \mu \mathrm{l}$. The mixture was heated for $5 \mathrm{~min}$ at $100^{\circ} \mathrm{C}$ and immediately cooled to $0^{\circ} \mathrm{C}$. Each $45-\mu \mathrm{l}$ sample was hybridized onto an miRNA array at $55^{\circ} \mathrm{C}$ for $20 \mathrm{~h}$. After hybridization, the slides were washed at room temperature for $5 \mathrm{~min}$ in Gene Expression Wash Buffer 1 and then for 5 min in Gene Expression Wash Buffer 2. The slides were scanned on an Agilent microarray scanner G2565A. The sensitivity settings were $100 \%$ and $5 \%$. Agilent Feature Extraction software version 9.5.3 was used for image analysis. The microarray data were analyzed using GeneSpring GX 7.3.1 (Agilent Technologies). The miRNA expression was considered significantly different when values in the muscles of the experimental rats were more than double of those of the sham-operated controls in 2 replicate experiments. ANOVA was employed to compare the average values of the miRNA probes in all samples and yielded significant $P$ values $(<0.05)$ in all cases.

\section{Quantification of miRNAs expression}

Those upregulated miRNAs (miR-21, miR-200c, and miR-205) that were identified from the miRNA array were quantified by real-time RT-PCR with the Applied Biosystems 7500 (Applied Biosystems, USA). We isolated total RNA from the harvested muscle with the mirVana miRNA Isolation Kit (Ambion, USA) as well as a TaqMan miRNA Assay kit (Applied Biosystems, USA) according to the manufacturers' instructions. The thermal cycling conditions comprised an initial denaturation step at $95^{\circ} \mathrm{C}$ for $10 \mathrm{~min}$ and 40 cycles at $95^{\circ} \mathrm{C}$ for $15 \mathrm{~s}$ and $60^{\circ} \mathrm{C}$ for 1 min. Each value of miRNA expression was represented relative to the expression of small RNA $4.5 \mathrm{~S}$, which was used as an internal control. The fold-expression of induction was calculated as the relative expression values obtained in each condition in conjunction with the standard deviation compared with the relative expression values from the gracilis muscles of the sham-operated control group. The comparison between the groups included ANOVA and the appropriate posthoc test to compensate for multiple comparisons (SigmaStat, San Rafael, CA, USA). P-values of less than 0.05 were considered significant.

\section{Whole Genome Microarray Analyses}

Four two-color Whole Rat Genome $4 \times 44 \mathrm{k}$ oligo microarrays (Agilent Technologies) were used to detect the change of the transcripts in the experimental gracilis muscles. Expression levels of the mRNAs in the gracilis muscles after $4 \mathrm{~h}$ of ischemia and $1,3,7$, and $14 \mathrm{~d}$ of reperfusion with 1 specimen at each of the abovementioned time points were detected with the oligo microarray and compared against those expression levels of the shamoperated control specimens at the same indicated time. The microarray experiments were carried out according to the manufacturer's protocols. In brief, $0.5 \mu \mathrm{g}$ of total RNA was amplified using a Fluorescent Linear Amplification Kit (Agilent Technologies) and labeled with Cy3CTP or Cy5-CTP (CyDye, PerkinElmer, CA, USA) during the in vitro transcription process. The RNA from the experimental muscle was labeled with $\mathrm{Cy} 5$ and the RNA from the sham-operated control muscle RNA was labeled with Cy3. Then, $0.825 \mu \mathrm{g}$ of the Cy-labeled cRNA was fragmented to an average size of about 50-100 nucleotides by incubation with the fragmentation buffer (Agilent Technologies) at $60^{\circ} \mathrm{C}$ for $30 \mathrm{~min}$. Subsequently, the fragmented labeled cRNA was pooled and hybridized to the Whole Rat Genome microarray at $60^{\circ} \mathrm{C}$ for $17 \mathrm{~h}$. After washing and drying with a nitrogen gun, the microarrays were scanned with an Agilent microarray scanner (Agilent Technologies) at $535 \mathrm{~nm}$ for Cy3 and $625 \mathrm{~nm}$ for Cy5. The scanned images were analyzed with the Feature Extraction software 9.5.3 (Agilent Technologies). We used image analysis and normalization software to quantify the signal and background intensity for each feature and to substantially normalize the data by the rank-consistency-filtering LOWESS method. The differentially expressed mRNAs were selected if there was a 2 -fold change between the experimental muscles and the shamoperated control muscles.

\section{Prediction of the potential target genes of miRNAs}

To date, there is not 1 algorithm that outperforms others in terms of sensitivity and specificity. We identified the potential targets of those upregulated miRNAs by combined analysis of the downregulated mRNAs in the whole genome expression microarray and the commonly used web tools for bioinformatics algorithms, including 3 of the most used prediction websites: miRanda http:// www.microrna.org/microrna/home.do, PicTar http://pictar.mdc-berlin.de/, and TargetScanS http://www.targetscan.org/, as well as 2 additional algorithms, MirTarget2 http://mirdb.org/miRDB/ and RNAhybrid http://bibiserv.techfak.uni-bielefeld.de/rnahybrid/. The in silico predicted targets genes were compared to the list of 2-fold downregulated mRNA transcripts (derived from the whole rat genome microarray experiments) by exam- 
ining miRNAs:mRNAs expression pairs in a time-course fashion. The genes that were identified in both methods were considered as potential target genes regulated by a given miRNA.

\section{Results}

\section{Expression profile of the miRNAs}

In the investigation of the differentially expressed miRNAs from the miRNA array experiments, there were only 3 miRNAs (miR-21, miR-200c, and miR-205) that showed an increased expression in the gracilis muscles after $4 \mathrm{~h}$ of ischemia and $4 \mathrm{~h}$ of reperfusion. We confirmed the microarray data by quantitative real-time RT-PCR to independently measure the relative expression of these 3 selected miRNAs in the samples of the experimental muscle. As shown in Figure 1, the 2-fold upregulation of miR-21 was detected after $4 \mathrm{~h}$ of ischemia and increased to a maximum of $\sim 24$ fold at $7 \mathrm{~d}$ after reperfusion. At 14 $\mathrm{d}$, there was still a 7.5-fold increased expression of miR21. The miR-200c expression was increased 3.2 fold and was detected $2 \mathrm{~h}$ after reperfusion following $4 \mathrm{~h}$ of ischemia. The expression of miR-200c reached its maximum level at $4 \mathrm{~h}$ and lasted for up to $8 \mathrm{~h}$ after ischemic injury. We did not detect an increased expression of miR-200c 1 $\mathrm{d}$ after reperfusion. A 6.4-fold upregulation of miR-205 was detected after $4 \mathrm{~h}$ of ischemia. It gradually decreased to 3.6 -fold at $4 \mathrm{~h}$ after reperfusion. No significant difference in the expression of miR-205 was found at $8 \mathrm{~h}, 1 \mathrm{~d}$, and $3 \mathrm{~d}$ after ischemic injury. Unexpectedly, we noted the 3.6-fold upregulation of miR-205 $7 \mathrm{~d}$ later. This status persisted until $14 \mathrm{~d}$ after ischemic injury. In the experiment that we performed to identify the minimal ischemic time that would induce the expression of these $3 \mathrm{miR}$ NAs, upregulation of miR-21 and miR-200c was noted after $4 \mathrm{~h}$ of reperfusion following $1 \mathrm{~h}$ and $2 \mathrm{~h}$, but not 30 min of ischemia; in addition, upregulation of miR-205 was noted after $4 \mathrm{~h}$ of reperfusion following $2 \mathrm{~h}$, but not $30 \mathrm{~min}$ or $1 \mathrm{~h}$ of ischemia (Figure 2).

\section{Finding the potential miRNA-regulated genes}

Time-course studies provide information for the identification of miRNA-target mRNA pairs that could often be missed in a cross-sectional study when a single time point is used [26]. Thus, we examined mRNA expression patterns at the 4 indicated times $(1,3,7$, and $14 \mathrm{~d}$ after ischemic injury) based on the matched analysis of miRNA and mRNA expression data and considered an miRNA to be regulatory only if the upregulation in the expression profile of the miRNA and its predicted target mRNAs correlated. The miR-200c and miR-205 were not upregulated at all 4 indicated times. In addition, there was still lack of evidence regarding the effect on the persistent knockdown of mRNAs by an elevated miRNA. Therefore, we decided to only focus on the genes that were downregulated by miR-21, which showed a persistent expression throughout the experiment period at all 4 indicated times. The expression profiling using the Agilent rat 60mer oligonucleotide microarrays showed there was a global pattern of differentially expressed genes at 1, 3, 7, and $14 \mathrm{~d}$ after ischemic injury. Expression profiling revealed that there were 1046 significantly downregulated gene transcripts in the experimental muscles (absolute expression changes were 2-fold or greater) at all 4 indicated times. In addition, the in silico prediction using the algorithms miRanda, PicTar, TargetScanS, MirTarget2, and RNAhybrid resulted in 957, 60, 159, 110, and 939 target genes of miR-21, respectively. The combination of the results of the computational prediction of
rno-miR-21

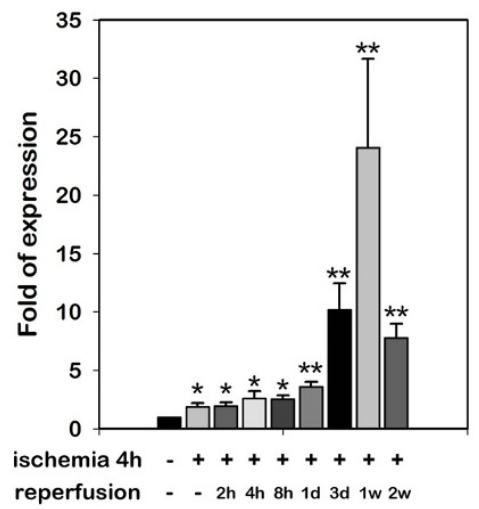

rno-miR-200c

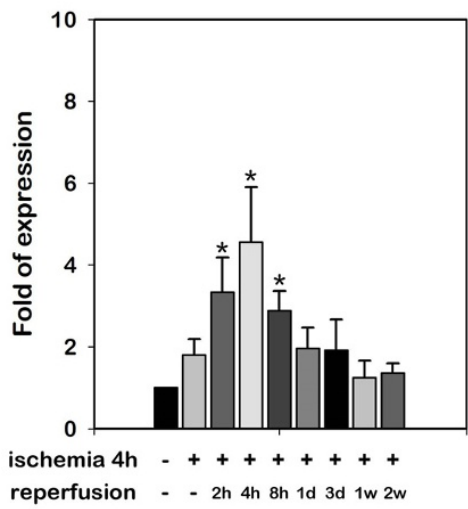

rno-miR-205

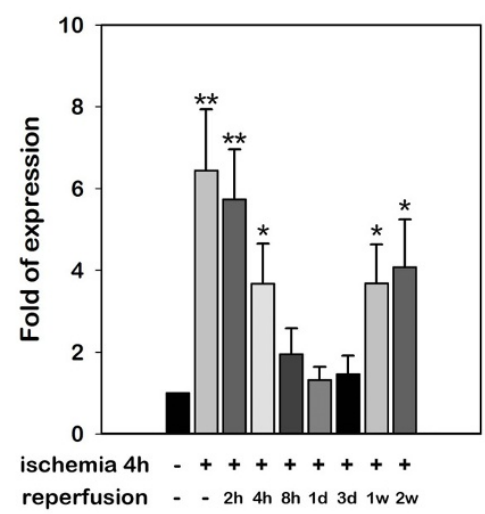

Figure 1 Expression of miR-21, miR-200c, and miR-205 detected with real-time RT-PCR in the gracilis muscles following $4 \mathrm{~h}$ of ischemia and reperfusion for indicated times. Bars represent means \pm standard deviation of 6 independent experiments; ${ }^{*}, P<0.05$ vs. sham-operated control. 

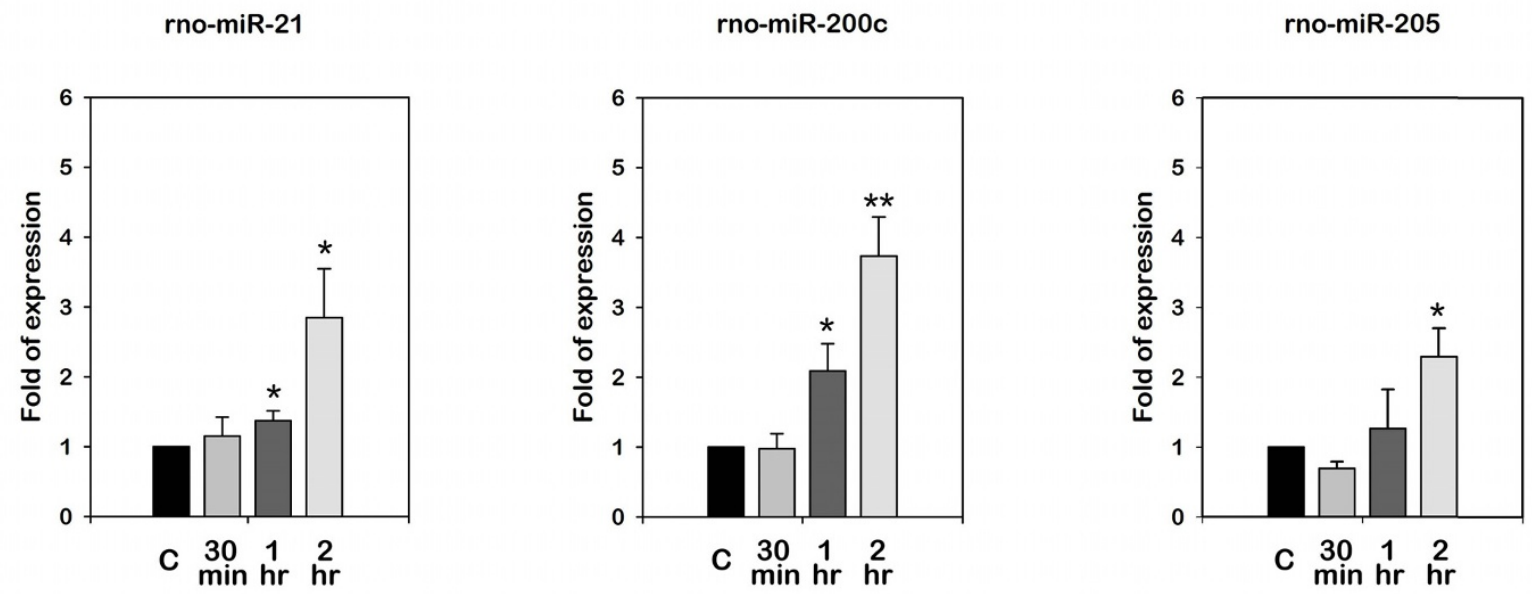

Figure 2 Expression of miR-21, miR-200c, and miR-205 detected with real-time RT-PCR in the gracilis muscles following indicated ischemic times $\left(\mathbf{3 0} \mathbf{~} \mathrm{min}, \mathbf{1} \mathbf{~ h}\right.$, and $\mathbf{2} \mathbf{~}$ ) and reperfusion for $\mathbf{4} \mathbf{~ h}$. Bars represent means \pm standard deviation of 5 independent experiments; ${ }^{*}, P<0.05 \mathrm{vs}$. shamoperated control.

target genes of miR-21 and the downregulation of genes in the whole genome expression array at 4 indicated times revealed no target gene on the basis of the prediction algorithms PicTar, TargetScanS, and MirTarget2; in contrast, when the prediction algorithms miRanda and RNAhybrid were applied, the same 4 target genes (Nqo1, Pdpn, CXCL3, and Rad23b) (Table 1) demonstrated a persistent downregulated status at 1, 3, 7, and $14 \mathrm{~d}$ (Figure 3). The miRNA array and the microarray data have been deposited in the Gene Expression Omnibus (accession number [GEO: GSE21423]).

\section{Discussion}

In this study, we demonstrated that 3 miRNAs (miR-21, miR-200c, and miR-205) were significantly upregulated in a different pattern in the gracilis muscles following ischemic injury. Ischemia for only $1 \mathrm{~h}$ was sufficient to induce the expression of miR-21 and miR-200c during the reperfusion stage; and $2 \mathrm{~h}$ of ischemia were required to induce the expression of miR-205. Our data also showed that miR-200c and miR-205 were actively regulated after ischemia but their expression pattern changed after reperfusion, indicating their temporal expression during ischemic injury. In addition, with a yet to be determined mechanism, we noted a significant re-expression of miR205 at 7 and $14 \mathrm{~d}$ after the injury. In contrast, the expression of miR-21 gradually increased to its maximum level at $7 \mathrm{~d}$ and persisted throughout the experiment for at least $14 \mathrm{~d}$ after the ischemic injury. This finding might imply an important role of miR-21 during ischemic injury in the muscle.

The overexpression of miR-21 has been shown to be in a number of medium-scale and high-scale profiling experiments that were designed for the detection of miRNAs that are dysregulated in cancer [27]. In addition, miR-21 has been reported to have anti-apoptotic properties in cancer cells $[28,29]$. It has been reported that miR21 protects against the hydrogen peroxide-induced injury

Table 1: The potential regulated gene targets of rno-miR-21

\begin{tabular}{llll}
\hline Symbol & Full Name & Transcript ID & Gene Type \\
\hline Nqo1 & NAD(P)H dehydrogenase, quinone 1 & $\underline{\text { ENSRNOT00000017174 }}$ & Protein coding \\
Pdpn & podoplanin & $\underline{\text { ENSRNOT00000020316 }}$ & Protein coding \\
Cxcl3 & chemokine (C-X-C motif) ligand 3 & $\underline{\text { ENSRNOT00000033592 }}$ & Protein coding \\
Rad23b & RAD23 homolog B & $\underline{\text { ENSRNOT00000021629 }}$ & Protein coding \\
\hline
\end{tabular}

Potential target genes of rno-miR-21 that were identified from downregulated mRNA in the experimental muscles in the whole genome expression array experiments after reperfusion for $1,3,7$, and $14 \mathrm{~d}$ following $4 \mathrm{~h}$ of ischemia as well as from either the miRanda or RNAhybrid prediction algorithm. 


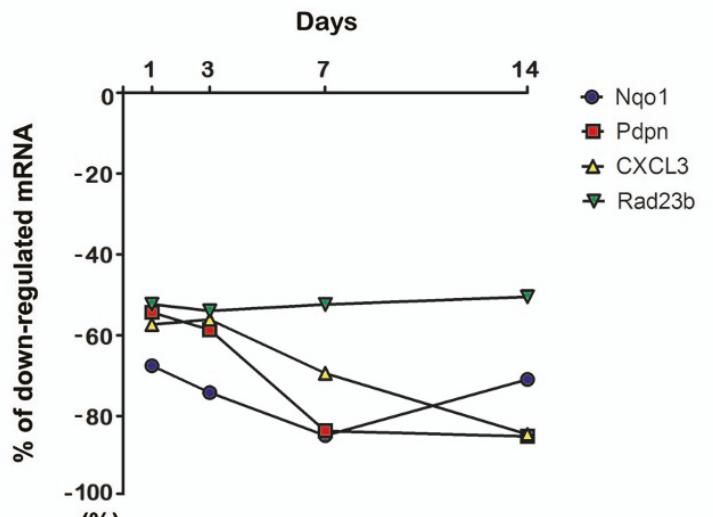

(\%)

Figure 3 The expression of down-regulated Nqo1, Pdpn, CXCL3, and Rad23b, which were the potential target genes of rno-miR-21 detected from the combined approach of the prediction algorithms miRanda and RNAhybrid, in the Whole Rat Genome $4 \times 44$ k oligo microarray experiments of the gracilis muscle after reperfusion for $1,3,7$, and $14 \mathrm{~d}$ following $4 \mathrm{~h}$ of ischemia.

of cardiac myocytes via its target gene, the repressor gene programmed cell death 4 (PDCD4), and the AP-1 pathway [30]. The hydrogen peroxide-induced cardiac cell death and apoptosis were increased by a miR-21 inhibitor and was decreased by pre-miR-21 transfection [30]. In addition, a significant induction of miR-21 was noted in the heart following whole body heat-shock [19]. The injection of chemically synthesized exogenous miR-21 significantly reduced infarct size in the heart which was blocked with a miR-21 inhibitor [19]. In an investigation of rat hearts at $6 \mathrm{~h}$ after acute myocardial injury, miRNA signatures in the early phase revealed that, among multiple aberrantly expressed miRNAs, miR-21 was significantly downregulated in infarcted areas, but was upregulated in border areas [31]. Remarkably, the downregulation of miR-21 in infarcted areas was inhibited by ischemic preconditioning, a known cardio-protective method. In addition, adenoviral overexpression of miR21 had a protective effect on myocardial infarction by decreasing the infarct size by $29 \%$ at $24 \mathrm{~h}$ [31]. In this study, we found 4 potential target genes (Nqo1, Pdpn, CXCL3, and Rad23b) of miR-21 during skeletal muscle ischemic injury. The database of experimentally validated miRNA target genes, MiRecords [32], lists 26 validated target genes of miR-21 in humans (TPM1, CDK6, TIMP3, PDCD4, SERPINB5, NFIB, CDKN1A, FAS, FAM3C, HIPK3, PRRG4, ACTA2, BTG2, BMPR2, SESN1, IL6R, SOCS5, GLCCI1, APAF1, SLC16A10, SGK3, RP2, CFL2, $R E C K, M T A P, S O X 5)$ and only 2 validated target genes in the rat (ITGB1, Tagln). Interestingly, the 4 genes that we identified in this study did not match with the already validated target genes in humans or rats. Among these 4 identified target genes, podoplanin (Pdpn) is a transmembrane glycoprotein and is expressed in many normal human tissues including the skeletal muscle [33]. Pdpn is widely used as a specific marker for lymphatic endothelial cells and lymphangiogenesis in many species because it is expressed on lymphatic but not on blood vessel endothelium [33]. Deficiency of Pdpn results in congenital lymphedema and impaired lymphatic vascular patterning [34]. With the postfix L (for ligand) or postfix R (for receptor), $\mathrm{CXCL}$ and $\mathrm{CXCR}$ are used as ligands and receptors of the $\mathrm{CXC}$ chemokine family which exhibits both angiogenic and angiostatic properties [35]. While chemokines can exert a pro-angiogenic effect via recruitment of inflammatory cells, CXCL3 is induced in the human perihematomal tissue [36] and can mediate angiogenesis in the absence of preceding inflammation [35]. The nucleotide excision repair (NER) protein, Rad23b, was found to be downregulated in hypoxic cancer cells [37]. Hypoxia can also promote genetic instability by affecting the DNA repair capacity, including NER which primarily focuses on helix-distorting injuries [38]. The downregulation of Rad23b in hypoxic cancer cells could be partially reversed by antisense inhibition of miR-373 [37], indicating a key role of miR-373 in modulating the basal expression of Rad23b. The effect of anti-miR-373 activity in normoxia is more profound than in hypoxia; thus, it has been suggested that there might be other mechanisms that regulate the expression of $\operatorname{Rad} 23 \mathrm{~b}$ [37]. In reviewing the literature, no direct linkage between these 4 identified target genes and the muscle ischemic injury was found. Only the detoxification enzyme $\mathrm{NAD}(\mathrm{P}) \mathrm{H}$ : quinone oxidoreductase 1 (Nqo1) could be correlated to the ischemic injury in renal tissue [39] and primary cultures of rat cortex [40], but with different outcomes regarding the cytoprotective effect. As a detoxification enzyme Nqo1 catalyzes the 2-electron reduction of quinoid compounds to the readily excreted hydroquinones, thereby preventing the generation of reactive oxygen species and protecting cells against oxidative damage [41]. The expression of the Nqo1 gene is primarily regulated via antioxidant response element sequences in the promoter region. Reoxygenation-specific activation of the antioxidant transcription factor Nrf2 mediates the cytoprotective gene expression during ischemia-reperfusion injury [42]. However, some authors suggested a deteriorating rather than a protective factor of $\mathrm{Nqo} 1$ in the progression of neuronal cell death, as inhibition of Nqo1 by various inhibitors protects against neuronal damage in vitro and following cerebral ischaemia in vivo [40]. Because bioinformatic analysis has indicated that miRNAs frequently interact with transcription factors in feedback and feedforward loops to regulate their target genes $[43,44]$; therefore, further experiments are required to elucidate the function and role of these potential target 
genes and the upregulated miR-21, as well as miR-200c and miR-205, in ischemic injury.

The pneumatic tourniquet is frequently used in surgery to acquire a bloodless operative field. To prevent the ischemia-reperfusion injury, the maximal allowable ischemic time of the pneumatic tourniquet is $2 \mathrm{~h}[45,46]$ Although minor histological changes in muscle started to appear after about 35-40 minutes, there was no clinical evidence

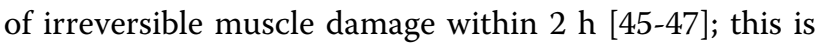
also the reason why most of the article studying the ischemic injury of skeletal muscle would choose the ischemic time at $4 \mathrm{~h}$ or a longer ischemic time. Whether there is a different miRNAs expression profile after a shorter time of ischemia such as $1 \mathrm{~h}$ or $2 \mathrm{~h}$ is unknown, but if these miRNAs are not up-regulated in a longer hour ischemia, the investigation of these targets may be devoid of clinical importance or attention. Therefore, in this study, we were not intended to profile the miRNAs expression with a miRNA array at a shorter time, like $2 \mathrm{~h}$, of ischemia. However, as shown in the Figure 2, in the investigation of minimal ischemic time that would induce the expression of these 3 miRNAs, we had demonstrated that $1 \mathrm{~h}$ of ischemia was able to increase the expression of miR-21 and $\mathrm{miR}-200 \mathrm{c}$ and $2 \mathrm{~h}$ of ischemia would increase the expression of these three miRNAs, implying the epigenetic regulation could be induced by a shorter time of ischemia before a remarked pathophysiologic change could be observed by a longer time of ischemia.

Bioinformatic algorithms remain the principal means of predicting targets of specific miRNAs. These algorithms take into account numerous parameters that influence miRNA/target interactions, including seed match (complementarity), 3'-UTR seed match context, seed match conservation, favorability of free energy binding, AU content, and binding site accessibility [48]. To identify miRNAs that regulate mRNAs, one needs to co-analyze the changes in miRNA and mRNA expressions. The investigation of the mRNA:miRNA association monitors the miRNA and mRNA expression on a genome-wide basis and provides an analytical approach to reveal the target genes of the miRNA [49,50]. However, some limitations still remain for the combined approach method that we described here. First, it might be overly simplistic to correlate miRNAs and their predicted targets primarily on the basis of the number of consensus sites in the 3'UTR because an exact match to the sequence of the seed region is not required. For example, miRanda typically produces more potential targets than other programs, but a large number of false targets would seriously limit the value of the output information [51]. In contrast, some available programs with stricter criteria, e.g., the prediction algorithms PicTar, TargetScanS, and MirTarget2 have only partially overlapping predicted targets for the same miRNA and produce smaller data sets than miRanda [52]. In this present study, in order to reduce the noise from the calculation of the correlation between miRNA and mRNAs (based on the time-course expression values), the inclusion of downregulated genes at all 4 time points might have been too strict to acquire potential target genes. In addition, it might have produced a smaller number of predicted targets after correlation with the stricter prediction algorithm considering the accuracy and reproducibility of the whole genome array. For example, no target genes were found for the combination with the prediction algorithms PicTar, TargetScanS, and MirTarget2. Due to the differences among databases and because there is no clear superior method, a further gain-of-function or loss-of function experiment would be helpful to elucidate the role of the identified target genes and that of each associated miRNA. Furthermore, it has been reported that more than a third of those translationally repressed target genes always displayed detectable mRNA destabilization [14]. However, the extent of miRNA function in animal cells has largely been studied by mRNA microarray profiling assuming that miRNA function leads to reduced mRNA levels, which may not be always the case. There might be some unidentified target genes that are repressed only in the translation process but have not been subjected to mRNA degradation.

\section{Conclusions}

This study has profiled an increased expression of miR21, miR-200c, and miR-205 in the gracilis muscle following ischemic injury and identified four potential target genes (Nqo1, Pdpn, CXCL3, and Rad23b) of the miR-21 by using different prediction algorithms and monitoring the expression of miRNA and mRNA at different time point on a genome-wide basis. Although the exact roles of these upregulated miRNAs following ischemic injury remains to be elucidated, this study provides a novel insight into the epigenetic regulation in the skeletal muscle following ischemic injury.

\section{List of abbreviations}

CXCL3: chemokine (C-X-C motif) ligand 3; miRNA: microRNA; Nqo1: NAD(P)H: quinone oxidoreductase 1; Pdpn: podoplanin; Rad23b: RAD23 homolog B.

\section{Competing interests}

The authors declare that they have no competing interests.

\section{Authors' contributions}

$\mathrm{CHH}$ was responsible for the design and coordination of the data acquisition and analysis, search for target genes via the computational algorithm, interpretation of the data, and the writing of the manuscript. JCJ and CJW participated in the real-time RT-PCR experiment. SFJ and PCL participated by providing and coordinating the resources. THL contributed to the animal surgery and acquisition of the study specimens. CSR participated in the analysis and interpretation of the data. YCC and CJ were involved in the acquisition of the miRNA array 
and whole genome expression data. All authors read and approved the final manuscript.

\section{Acknowledgements}

The work was supported by the National Science Committee (NSC 98-2314-B182A-024-MY3) and the Chang Gung Memorial Hospital (CMRPG 871001), Taiwan.

\section{Author Details}

1Department of Plastic and Reconstructive Surgery, Chang Gung Memorial Hospital, Kaohsiung Medical Center, Chang Gung University College of Medicine, Taiwan, 2Business BA at University of Texas at Dallas, 800 W Campbell Road, Richardson, TX 75080, USA, ${ }^{3}$ Department of Neurosurgery, E-Da Hospital, I-Shou University, Kaohsiung, Taiwan and 4Department of Neurosurgery, Chang Gung Memorial Hospital, Kaohsiung Medical Center, Chang Gung University College of Medicine, Taiwan

Received: 18 December 2009 Accepted: 17 June 2010 Published: 17 June 2010

\section{References}

1. Lyden SP, Shortell CK, Illig KA: Reperfusion and compartment syndromes: strategies for prevention and treatment. Semin Vasc Surg 2001, 4(2):107-113.

2. Kloosterman WP, Plasterk $\mathrm{RH}$ : The diverse functions of microRNAs in animal development and disease. Dev Cell 2006, 11(4):441-450.

3. Zhao Y, Srivastava D: A developmental view of micro-RNA function. Trends Biochem Sci 2007, 2(4):189-197.

4. Ambros V: The functions of animal microRNAs. Nature 2004, 431(7006):350-355.

5. Hwang HW, Mendell JT: MroRNAs in cell proliferation, cell death, and tumorigenesis. Br J Cancer 2006, 94(6):776-780.

6. Jovanovic M, Hengartner MO: miRNAs and apoptosis: RNAs to die for. Oncogene 2006, 25(46):6176-6187.

7. Lewis BP, Burge CB, Bartel DP: Conserved seed pairing, often flanked by adenosines, indicates that thousands of human genes are microRNA targets. Cell 2005, 120(1):15-20.

8. Brennecke J, Stark A, Russell RB, Cohen SM: Principles of microRNA-target recognition. PLoS Biol 2005, 3(3):e85.

9. Rajewsky N: microRNA target predictions in animals. Nat Genet 2006, 38:S8-S13.

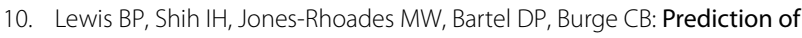
mammalian microRNA targets. Cell 2003, 115(7):787-798.

11. Meister G, Tuschl T: Mechanisms of gene silencing by double-stranded RNA. Nature 2004, 431(7006):343-349.

12. Nilsen TW: Mechanisms of microRNA-mediated gene regulation in animal cells. Trends Genet 2007, 23(5):243-249.

13. Pillai RS, Bhattacharyya SN, Filipowicz W: Repression of protein synthesis by miRNAs: how many mechanisms? Trends Cell Bio/ 2007, 17(3):118-126.

14. Baek D, Villén J, Shin C, Camargo FD, Gygi SP, Bartel DP: The impact of microRNAs on protein output. Nature 2008, 455(7209):64-71.

15. Guimbellot JS, Erickson SW, Mehta T, Wen H, Page GP, Sorscher EJ, Hong $\mathrm{JS}$ : Correlation of microRNA levels during hypoxia with predicted target mRNAs through genome-wide microarray analysis. BMC Med Genomics 2009, 25:15.

16. Jeyaseelan K, Lim KY, Armugam A: MicroRNA expression in the blood and brain of rats subjected to transient focal ischemia by middle cerebral artery occlusion. Stroke 2008, 39(3):959-966.

17. Dharap A, Bowen K, Place R, Li LC, Vemuganti R: Transient focal ischemia induces extensive temporal changes in rat cerebral microRNAome. $J$ Cereb Blood Flow Metab 2009, 29(4):675-687.

18. Ren XP, Wu J, Wang X, Sartor MA, Qian J, Jones K, Nicolaou P, Pritchard TJ, Fan GC: MicroRNA-320 is involved in the regulation of cardiac ischemia/reperfusion injury by targeting heat-shock protein 20. Circulation 2009, 119(17):2357-2366.

19. Yin C, Wang X, Kukreja RC: Endogenous microRNAs induced by heatshock reduce myocardial infarction following ischemia-reperfusion in mice. FEBS Lett 2008, 582(30):4137-4142.

20. Tatsuguchi M, Seok HY, Callis TE, Thomson JM, Chen JF, Newman M, Rojas M, Hammond SM, Wang DZ: Expression of microRNAs is dynamically regulated during cardiomyocyte hypertrophy. J Mol Cell Cardiol 2007, 42(6):1137-1141.

21. van Rooij E, Sutherland LB, Liu N, Williams AH, McAnally J, Gerard RD, Richardson JA, Olson EN: A signature pattern of stress-responsive microRNAs that can evoke cardiac hypertrophy and heart failure. Proc Natl Acad Sci USA 2006, 103(48):18255-18260.

22. Eisenberg I, Eran A, Nishino I, Moggio M, Lamperti C, Amato AA, Lidov HG, Kang PB, North KN, Mitrani-Rosenbaum S, Flanigan KM, Neely LA, Whitney D, Beggs AH, Kohane IS, Kunkel LM: Distinctive patterns of microRNA expression in primary muscular disorders. Proc Natl Acad Sci USA 2007, 104(43):17016-17021

23. Callis TE, Chen JF, Wang DZ: MicroRNAs in skeletal and cardiac muscle development. DNA Cell Biol 2007, 26(4):219-225.

24. Wang $H$, Sun $H$, Guttridge DC: microRNAs: novel components in a muscle gene regulatory network. Cell Cycle 2009, 8(12):1833-1837.

25. Potthoff MJ, Olson EN, Bassel-Duby R: Skeletal muscle remodeling. Curr Opin Rheumatol 2007, 19(6):542-549.

26. Jayaswal V, Lutherborrow M, Ma DD, Hwa Yang Y: Identification of microRNAs with regulatory potential using a matched microRNAmRNA time-course data. Nucleic Acids Res 2009, 37(8):e60.

27. Krichevsky AM, Gabriely G: miR-21: a small multi-faceted RNA. J Cell Mol Med 2009, 13(1):39-53

28. Meng F, Henson R, Lang M, Wehbe H, Maheshwari S, Mendell JT, Jiang J, Schmittgen TD, Patel T: Involvement of human micro-RNA in growth and response to chemotherapy in human cholangiocarcinoma cell lines. Gastroenterology 2006, 130(7):2113-2129.

29. Chan JA, Krichevsky AM, Kosik KS: MicroRNA-21 is an antiapoptotic factor in human glioblastoma cells. Cancer Res 2005, 65(14):6029-6033.

30. Cheng Y, Liu X, Zhang S, Lin Y, Yang J, Zhang C: MicroRNA-21 protects against the $\mathrm{H} 2 \mathrm{O} 2$-induced injury on cardiac myocytes via its target gene PDCD4. J Mol Cell Cardiol 2009, 47(1):5-14.

31. Dong S, Cheng Y, Yang J, Li J, Liu X, Wang X, Wang D, Krall TJ, Delphin ES, Zhang C: MicroRNA expression signature and the role of microRNA-21 in the early phase of acute myocardial infarction. J Biol Chem 2009, 284(43):29514-29525.

32. Xiao F, Zuo Z, Cai G, Kang S, Gao X, Li T: miRecords: an integrated resource for miRNA-target interactions. Nucleic Acids Res 2009:D105-110.

33. Wicki A, Christofori G: The potential role of podoplanin in tumour invasion. Br J Cancer 2007, 96(1):1-5.

34. Schacht V, Ramirez MI, Hong YK, Hirakawa S, Feng D, Harvey N, Williams M, Dvorak AM, Dvorak HF, Oliver G, Detmar M: T1alpha/podoplanin deficiency disrupts normal lymphatic vasculature formation and causes lymphedema. EMBO J 2003, 22(14):3546-3556.

35. Shireman PK: The Chemokine System in Arteriogenesis and Hind Limb Ischemia. J Vasc Surg 2007, 45(Suppl A):A48-A56.

36. Carmichael ST, Vespa PM, Saver JL, Coppola G, Geschwind DH, Starkman S, Miller CM, Kidwell CS, Liebeskind DS, Martin NA: Genomic profiles of damage and protection in human intracerebral hemorrhage. $J$ Cereb Blood Flow Metab 2008, 28(11):1860-1875.

37. Crosby ME, Kulshreshtha R, Ivan M, Glazer PM: MicroRNA regulation of DNA repair gene expression in hypoxic stress. Cancer Res 2009, 69(3):1221-1229.

38. Ng JM, Vermeulen W, van der Horst GT, Bergink S, Sugasawa K, Vrieling $H$, Hoeijmakers $\mathrm{JH}$ : A novel regulation mechanism of DNA repair by damage-induced and RAD23-dependent stabilization of xeroderma pigmentosum group C protein. Genes Dev 2003, 17(13):1630-1645.

39. Leonard MO, Kieran NE, Howell K, Burne MJ, Varadarajan R, Dhakshinamoorthy S, Porter AG, O'Farrelly C, Rabb H, Taylor CT: Reoxygenation-specific activation of the antioxidant transcription factor Nrf2 mediates cytoprotective gene expression in ischemiareperfusion injury. FASEB J 2006, 20(14):2624-2626.

40. Kapinya KJ, Harms U, Harms C, Blei K, Katchanov J, Dirnagl U, Hörtnagl H: Role of $\mathrm{NAD}(\mathrm{P}) \mathrm{H}$ :quinone oxidoreductase in the progression of neuronal cell death in vitro and following cerebral ischaemia in vivo. $J$ Neurochem 2003, 84(5):1028-1039.

41. Sasaki S, Sata F, Katoh S, Saijo Y, Nakajima S, Washino N, Konishi K, Ban S, Ishizuka M, Kishi R: Adverse birth outcomes associated with maternal smoking and polymorphisms in the N-Nitrosamine-metabolizing enzyme genes NQO1 and CYP2E1. Am J Epidemiol 2008, 167(6):719-726.

42. Leonard MO, Kieran NE, Howell K, Burne MJ, Varadarajan R, Dhakshinamoorthy S, Porter AG, O'Farrelly C, Rabb H, Taylor CT: 
Reoxygenation-specific activation of the antioxidant transcription factor Nrf2 mediates cytoprotective gene expression in ischemiareperfusion injury. FASEB J 2006, 20(14):2624-2626.

43. Martinez NJ, Ow MC, Barrasa MI, Hammell M, Sequerra R, DoucetteStamm L, Roth FP, Ambros VR, Walhout AJ: A C. elegans genome-scale microRNA network contains composite feedback motifs with high flux capacity. Genes Dev 2008, 22(18):2535-2549.

44. Tsang J, Zhu J, van Oudenaarden A: MicroRNA-mediated feedback and feedforward loops are recurrent network motifs in mammals. Mol Cell 2007, 26(5):753-767.

45. Solonen KA, Hjelt L: Morphological changes in striated muscle during ischaemia. Acta Orthop Scand 1968, 39:13-19.

46. Fletcher IR, Healy TE: The arterial tourniquet. Ann R Coll Surg Engl 1983, 65(6):409-417.

47. Patterson $S$, Klenerman $L$ : The effect of pneumatic tourniquets on the ultrastructure of skeletal muscle. J Bone Joint Surg Br 1979, 61(2):178-183.

48. Bartel DP: MiRNAs: target recognition and regulatory functions. Cell 2009, 136(2):215-233.

49. Jeng SF, Rau CS, Liliang PC, Wu CJ, Lu TH, Chen YC, Lin CJ, Hsieh CH: Profiling muscle-specific microRNA expression after peripheral denervation and re-innervation in a rat model. J Neurotrauma 2009, 26(12):2345-53.

50. Hsieh CH, Rau CS, Jeng SF, Lin CJ, Chen YC, Wu CJ, Lu TH, Lu CH, Chang WN: Identification of the potential target genes of microRNA-146a induced by PMA treatment in human microvascular endothelial cells. Exp Cell Res 2010, 316(7):1119-1126.

51. Yousef M, Showe L, Showe M: A study of microRNAs in silico and in vivo: bioinformatics approaches to microRNA discovery and target identification. FEBS J 2009, 276(8):2150-2156.

52. Guimbellot JS, Erickson SW, Mehta T, Wen H, Page GP, Sorscher EJ, Hong JS: Correlation of microRNA levels during hypoxia with predicted target mRNAs through genome-wide microarray analysis. BMCMed Genomics 2009, 25:15.

\section{Pre-publication history}

The pre-publication history for this paper can be accessed here: http://www.biomedcentral.com/1471-2474/11/123/prepub

Submit your next manuscript to BioMed Centra and take full advantage of:

- Convenient online submission

- Thorough peer review

- No space constraints or color figure charges

- Immediate publication on acceptance

- Inclusion in PubMed, CAS, Scopus and Google Scholar

- Research which is freely available for redistribution

Submit your manuscript at www.biomedcentral.com/submit
C Biomed Central 